\title{
Use of Cocoa Ethanolic Extract for Treatment of Staphylococcal Infection in Rabbit-Skin Model
}

\author{
Ariza Budi Tunjung-Sari ${ }^{\left.{ }^{*}\right)}$, Teguh Wahyudi ${ }^{12}$, Diana Chusna Mufida ${ }^{2}$, Mekania Tamarizki²), \\ Desyana Perwitahati ${ }^{2}$, Ihda Kartika Syamsuddin ${ }^{2)}$ and Misnawi ${ }^{1)}$

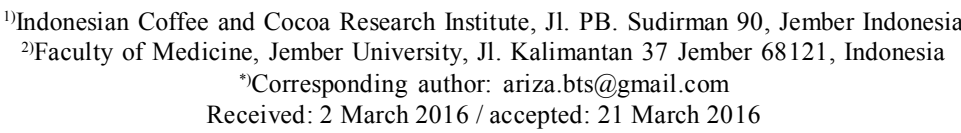

\begin{abstract}
In septic condition, the skin normal flora Staphylococcal spp. may trigger local and sistemic skin infection. In this study antibacterial activity of cocoa ethanolic extract (CEE) against Staphylococcus aureus and Staphylococcus epidermidis infections was observed in vitro and in vivo. Ethanolic extract from unfermented cocoa beans was prepared as solution in the in vitro testing, while for in vivo testing the extract was prepared as cream. Agar well diffusion assay showed that CEE ranging from $7.8 \mathrm{mg} / \mathrm{mL}$ to $1000 \mathrm{mg} / \mathrm{mL}$ demonstrated inhibitory activity against growth of either $S$. aureus and $S$. epidermidis. Inhibitory activity of $\mathrm{CEE}$ was in concentration dependent manner, and was less potential than either cephalexin $4 \times 10^{-3} \mathrm{mg} / \mathrm{mL}$ or cefotaxime $8 \times 10^{-3} \mathrm{mg} / \mathrm{mL}$. Linear regression of CEE concentration plotted against inhibition zone values had predicted the minimum inhibitory concentrations (MIC) of CEE towards $S$. aureus and S. epidermidis were at $341.9 \mathrm{mg} / \mathrm{mL}$ and $359.7 \mathrm{mg} / \mathrm{mL}$, respectively. Topical application of cream containing CEE at several concentrations $(2 \%, 4 \%$, and $8 \%)$ demonstrated healing properties towards incision wound infected with $S$. aureus and $S$. epidermidis cultures in rabbit-skin model. CEE cream promoted wound contraction and higher recovery rate than of base cream (negative control) but lower than mupirocin $2 \%$ cream. In $S$. aureus and $S$. epidermidis infected wound models, CEE cream $8 \%$ improved wound recovery to $72.7 \%$ and $86.1 \%$ from original rates of $23.5 \%$ and $34.7 \%$ (base cream application). Catechin and procyanidis are suggested playing roles in alleviation of wound inflammation and stimulation of extracellular matrix accumulation, thus accelerate the wound healing process. This study proposes utilization of cocoa bean as source of active ingredient for skin care products.
\end{abstract}

Keywords: cocoa, polyphenol, staphylococcus, rabbit-skin model, wound

\section{INTRODUCTION}

Global burden studies in 2010 noticed that skin health management should earn global concern, since nonfatal diseases were initiated from skin (Hay et al., 2013). Skin is the habitat of microorganisms where commensal relationship is developed and there are conditions when normal skin residents shift into pathogenic state and induce local and systemic diseases (Dryden, 2009). Staphylococcus aureus and Staphylococcus epidermidis are parts of skin normal flora and regularly found in healthy human skin at any age (Oh et al., 2012; Otto, 2009). Staphylococcus aureus may generate local 
infection in skin and soft tissue such as impetigo, folliculitis, boils, carbuncles and myositis. Systemic infection triggers toxic shock and scalded skin syndrome, whose symptoms are rash and desquamation on skin (Dryden, 2009). Staphylococcus epidermidis is iniator of most nosocomial infections which transmitted through indwelling medical devices (Otto, 2012). Its was estimated that United State of America spent about USD 2 billion for treatment of bloodstream infection due to S. epidermidis (Otto, 2009).

Staphylococci gained more attention since some strains showed decreasing susceptibility toward antibiotics. Ability to form biofilm has protected themselves from penetration of methycillin, thus lead to emergence of methycillin-resistant staphylococci (Singh et al., 2010). Consequently, attempt to treat staphylococcal skin infection demands new antibacterial agents. Studies have observed antibacterial potency of several plant extracts, and reported efficacy of Vitis vinifera L. (Al-Habib et al., 2010), Turnera ulimifolia L. (Coutinho et al., 2009), and some indigenous plants extracts (Ali et al., 2011; LucianoMontalvo et al., 2013; Naveed et al., 2013) to inhibit growth and virulence of $S$. aureus and S. epidermidis.

Cocoa (Theobroma cacao L.) is native plant of Amazon basin, which was utilized for ritual servings, currency and medicine (Dillinger et al., 2000; Lippi, 2009). The medicinal use is coming along with deposits of nutrients and phenolic compounds. New perspective expands the use of cocoa bean not only for confectioneries but also for functional foods. Recent consumers are motivated to eat chocolate and cocoa products, in order to obtain health benefit of cocoa which consist of macronutrients and micronutrients. Cocoa powder which has undergone fermentation, roasting, fat removal and grinding, is rich of carbohydrate, dietary fiber and protein, and is a good source of potassium, phosphorus and magnesium. Cocoa also provides catechin, a member of plant phenolic compound that is associated with various health impacts, from antioxidant to anticancer. The total polyphenol content in cocoa reaches $48.2 \pm$ $2.2 \mathrm{mg} / \mathrm{g}$. The phenolic fraction in that cocoa demonstrated inhibitory activity against gram negative bacteria, i.e. Escherichia coli and Shigella dysentriae (Crozier et al., 2011; Sari et al., 2014; Misnawi et al., 2015). This study is aimed to investigate antibacterial potency of polyphenol-rich cocoa ethanolic extract against $S$. aureus and $S$. epidermidis. Bacteria growth inhibition was assessed in vitro through agar well diffusion assay, while its effect on infected wound was evaluated in rabbit-skin model.

\section{MATERIALS AND METHODS}

Cocoa ethanolic extract (CEE) was prepared by soaking cocoa powder (fat removed, unroasted, unfermented) in ethanol for overnight. Liquid was filtered and was concentrated using vacum evaporator resulted in powder of CEE. For in vitro assay, the CEE powder was gradually diluted in water to reach concentrations of $1000 \mathrm{mg} / \mathrm{mL}$, $500 \mathrm{mg} / \mathrm{mL}, 250 \mathrm{mg} / \mathrm{mL}, 125 \mathrm{mg} / \mathrm{mL}, 62.5 \mathrm{mg} /$ $\mathrm{mL}, 31.2 \mathrm{mg} / \mathrm{mL}, 15.6 \mathrm{mg} / \mathrm{mL}$, and $7.8 \mathrm{mg} /$ $\mathrm{mL}$. Positive control was chosen based on drug of choice for $S$. aurens and $S$. epidermis which were cephalexin $\left(4 \times 10^{-3} \mathrm{mg} / \mathrm{mL}\right)$ and cefotaxime $\left(8 \times 10^{-3} \mathrm{mg} / \mathrm{mL}\right)$, respectively. For in vivo test, cream of CEE was prepared by homogenizing CEE powder with mixture of stearic acid, cerae albi, vaseline albi, triethanolamine, propilen glycol and distilled water. Cream may contain CEE at concentration $2 \%, 4 \%$ or $8 \%$. 
S. aureus and S.epidermidis cultures $\left(10^{8} \mathrm{CFU} / \mathrm{mL}\right)$ were seeded by swapping onto plated Mueller-Hinton agar medium. Sterile cork borer was used to create 4 wells on each plate and CEE solution at certain concentration was poured into well. Plates were incubated at $37^{\circ} \mathrm{C}$ for 24 hours. Clear area developed around well indicated bacteria growth inhibition by test sample. Antibacterial activity was evaluated by measuring outer radius of inhibition zone subtracted by outer radius of well. Positive control for in vitro assay were first line antibiotics, cephalexin $4 \times 10^{-3} \mathrm{mg} / \mathrm{mL}$ and cefotaxime $8 \times 10^{-3} \mathrm{mg} / \mathrm{mL}$, while negative control was ssterile distilled water. Minimum inhibitory concentration (MIC) is the concentration of CEE that resulted inhibitory zore $\geq 6 \mathrm{~mm}$.

Ten albino rabbits aged 3 months (2.5$3 \mathrm{~kg}$ ) were acclimatized for one week prior to treatment. Dorsal fur was clipped and dorsal skin was anesthetized by subcutaneous injection of one $\mathrm{mL}$ lidocain. Skin was incised $2.5 \mathrm{~cm}$ using sterile surgical blade, and was infected by intracutaneous injection of $0.5 \mathrm{~mL} S$. aureus or S. epidermidis culture. Wound was covered with sterile gauze and adhesive bandage. After $24 \mathrm{~h}$, test sample was applied on wound three times daily for the next seven days. Gauze was replaced with new ones after application. Development of wound was observed by including criteria of erythema, while wound opening was measured daily by using caliper. Wound recovery level was calculated based on closure wound length (CWL) as follow:

Closure rate $(\%)=$

$$
\frac{\text { CWL (h-1) - CWL (h-7) }}{\text { CWL (h-1) }}
$$

Positive control for in vivo assay was mupirocin $2 \%$ cream, while negative control was base cream with no active ingredient. The trial had acquired ethical approval from Faculty of Medicine, University of Jember.
Experiment was done in triplicates and statistical analysis of the data employed t-test, analysis of variance and MannWhitney test for post-hoc analysis. The MIC values from in vitro trial were determined by employing linear regresion.

\section{RESULTS AND DISCUSSION}

CEE showed ability to inhibit growth of gram positive bacteria which are $S$. aureus and $S$. dysenteriae in Mueller-Hinton agar after $24 \mathrm{~h}$ incubation. Inhibitory activity towards $S$. aureus was much greater than that of S. epidermidis (t-test, $\mathrm{P}<0.05$ ) and this occured in concentration-dependent manner. CEE at concentration below $15.6 \mathrm{mg} /$ $\mathrm{mL}$ was not effective to inhibit bacteria growth. There was no inhibition zone found under presence of CEE at $7.8 \mathrm{mg} / \mathrm{mL}$ where this result was similar to negative control (sterile distilled water). Compared to cephalexin and cefotaxime, CEE has lower antibacterial potency. Cephalexin $\left(4 \times 10^{-3} \mathrm{mg} / \mathrm{mL}\right)$ created $8.05 \mathrm{~mm}$ inhibition zone against $S$. aureus, which is greater than inhibition zone of CEE at $1000 \mathrm{mg} /$ $\mathrm{mL}(7.75 \mathrm{~mm})$. The same situation was demostrated by cefotaxime $\left(8 \times 10^{-3} \mathrm{mg} /\right.$ $\mathrm{mL})$ against $S$. epidermidis that produced inhibition zone $(12.50 \mathrm{~mm})$ greater than $\mathrm{CEE}$ at $1000 \mathrm{mg} / \mathrm{mL}(7.7 \mathrm{~mm})$.

In the in vitro trial annular radius of inhibition zone is representing antibacterial potency of test substance. Test substance that develops inhibition zone $\geq 6 \mathrm{~mm}$ is considered inducing bacteria susceptibility (Bell et al., 2011). Minimum inhibitory concentration (MIC) of CEE is the lowest concentration that resulted inhibition zone $\geq 6 \mathrm{~mm}$. Regression method showed that MIC of CEE against $S$. aureus and $S$. epidermidis were $341.9 \mathrm{mg} / \mathrm{mL}\left(\mathrm{R}^{2}=0.995\right)$ and $359.7 \mathrm{mg} / \mathrm{mL}$ $\left(\mathrm{R}^{2}=0.910\right)$, respectively. This assay showed 
Table 1. Inhibition zone of test substance in bacteria-seeded agar plate

\begin{tabular}{lrc}
\hline \multirow{2}{*}{ Test sample } & \multicolumn{2}{c}{ Annular radius of inhibition zone, mm } \\
\cline { 2 - 3 } CEE $1000 \mathrm{mg} / \mathrm{mL}$ & $15.5 \pm 0.5$ & S. epidermidis \\
CEE $500 \mathrm{mg} / \mathrm{mL}$ & $9.6 \pm 0.6$ & $9.2 \pm 0.3$ \\
CEE $250 \mathrm{mg} / \mathrm{mL}$ & $2.3 \pm 0.5$ & $7.7 \pm 0.8$ \\
CEE $125 \mathrm{mg} / \mathrm{mL}$ & $11.0 \pm 0.9$ & $5.0 \pm 01$ \\
CEE $62.5 \mathrm{mg} / \mathrm{mL}$ & $4.1 \pm 0.4$ & $2.6 \pm 0.7$ \\
CEE $31.2 \mathrm{mg} / \mathrm{mL}$ & $12.7 \pm 0.3$ & $1.5 \pm 0.0$ \\
CEE $15.6 \mathrm{mg} / \mathrm{mL}$ & $6.5 \pm 1.0$ & $1.2 \pm 3.5$ \\
CEE $7.8 \mathrm{mg} / \mathrm{mL}$ & $0.0 \pm 0.0$ & $0.5 \pm 0.1$ \\
Sterile distilled water & $0.0 \pm 0.0$ & $0.0 \pm 0.0$ \\
Cephalexin $4 \times$ x $10^{-3} \mathrm{mg} / \mathrm{mL}$ & $16.1 \pm 0.6$ & $0.0 \pm 0.0$ \\
Cefotaxime $8 \times 10^{-3} \mathrm{mg} / \mathrm{mL}$ & NA & $\mathrm{NA}$ \\
Notes: Data are means of three replications; $\pm=$ standard deviation; NA $=$ not applicable; * $=$ data were not significantly \\
$\quad$ different based on Mann-Whitney post-hoc test $(\mathrm{a}=0.05)$.
\end{tabular}

that MIC against $S$. aureus was lower than against $S$. epidermidis, suggesting that $S$. aureus is more susceptible toward CEE.

CEE cream at several concentrations demonstrated ability to promote wound recovery on rabbit skin model as indicated from length of wound closure (Table 2). In general, CEE promoted recovery of $S$. epidermidis infected wound better than $S$. aureus infected wound (t-test, $\mathrm{P}<0.01$ ). Wound closure of $S$. aureus-infected wound was originally $23.60 \%$ (base cream) and was promoted by topical application of CEE cream into $41.20 \%$ (CEE 2\%); $57.20 \%$ (CEE 4\%) and $72.80 \%$ (CEE 8\%). Towards S. epidermidisinfected wound, CEE cream has successfully increased recovery level from $34.72 \%$ (base cream) to $50.56 \%$ (CEE 2\%); $66.40 \%$ (CEE 4\%) and 86.08\% (CEE 8\%). Compared to mupirocin $2 \%$ cream as positive control, ability of CEE to promote wound recovery was lower. At concentration $4 \%$ and $8 \%$, CEE promoted recovery of $S$. epidermidisinfected wound better than $S$. aureus-infected wound ( $P<0,01)$. This result is in contrary to in vitro assay which indicates $S$. aureus was more susceptible against CEE rather than $S$. epidermidis.
Catechin may polymerize to form procyanidin (proanthocyanin) which consists of at least two binding catechins. Isomers of catechin exist in the form of $(+)$-catechin, $(-)$-catechin, (+)-epicatechin and (-)-epicatechin. Research by Misnawi et al. (2002) indicated degradation of polyphenol during cocoa fermentation, whereas 5-day fermentation reduces total polyphenol content as much as $58 \%$. Furthermore, a process known as alkalization ('Dutch' process) aimed to increase color intensity of cocoa powder, reduces total phenol content more than $90 \%$ (Miller et al., 2008). In this experiment, we attempted to conserve phenolic compound in cocoa bean by avoiding fermentation and roasting process. Powdered ethanolic extract of cocoa bean provides concentrated phenols, with total phenol content was $14 \%$ (expressed as (+)-catechin equivalent) or $29.7 \mathrm{~g}$ (gallic acid equivalent) per $100 \mathrm{~g}$ powder. This amount is much higher than $100 \mathrm{~g}$ of natural cocoa powder that provides $6.32 \mathrm{~g}$ polyphenol (gallic acid equivalent) (Miller et al., 2008).

Oral and topical administrations of cocoa, in the form of butter, dark chocolate or cocoa powder, have shown benefits to skin condition. During inflammatory stage, 
Tunjung-Sari et al.

Table 2. Length of wound closure with respect to bacteria infection

\begin{tabular}{|c|c|c|c|c|}
\hline \multirow{3}{*}{ Treatment } & \multicolumn{4}{|c|}{ Wound closure, $\mathrm{cm}$} \\
\hline & \multicolumn{2}{|c|}{ S. aureus infection } & \multicolumn{2}{|c|}{ S. epidermidis infection } \\
\hline & $\mathrm{H}-7$ & Closure, $\%$ & $\mathrm{H}-7$ & Closure, \% \\
\hline Base cream & $1.9 \pm 0.0$ & 23 & $1.7 \pm 0.3$ & 31 \\
\hline CEE $2 \%$ cream & $1.5 \pm 0.1$ & 41 & $1.2 \pm 0.0$ & 53 \\
\hline CEE $4 \%$ cream & $1.1 \pm 0.1$ & 57 & $0.8 \pm 0.1$ & 68 \\
\hline CEE $8 \%$ cream & $0.7 \pm 0.0$ & 73 & $0.3 \pm 0.1$ & 87 \\
\hline Mupirocin $2 \%$ cream & $0.3 \pm 0.0$ & 89 & $0.1 \pm 0.0$ & 93 \\
\hline
\end{tabular}

immune response is also promoted by cocoa flavanols due to increasing blood flow to dermal area (Neukam et al., 2007). Moreover, studies suggested cocoa flavonoids alleviate inflammation, by modulating immune cells activity and secretion of pro-inflammatory signaling molecules (García-Lafuente et al., 2009). Wound contraction is enhanced by presence of tannin, thus enabling connectivity of dermal tissue. Li et al. (2011) reported that enhanced wound contraction after topical application of tannin with comparable result to erythromycin ointment.

Antibacterial activity of plant phenols has been attributed with its high affinity to bacterial cell wall (Johnson et al., 2008; Matsumoto et al., 2012). Attachment of phenolic compound to bacterial cell causes membrane destabilization and induces cell leakage (Bernal et al., 2010; PuupponenPimiä et al., 2005). Penetration of phenolic compounds into bacterial cell may reach genetic material and disrupt nucleic acid synthesis, particularly by binding with topoisomerases (Bandele et al., 2008; Suriyanarayanan et al., 2013). Disruption of cell function occures when phenolic compounds interact with proteins and cytoplasmic consituents (Radulovic et al, 2013). Gram negative bacteria is more resistant than gram positive bacteria, due to its outer membrane providing barrier towards antimicrobial agent. However, gram positive bacteria is equipped with ability to form biofilm. Biofilm is not only protecting cells from antibacterial agents but also contributing to bacteria virulence (Hall-Stoodley et al., 2004).

Rabbit skin infection model demonstrated wound infection triggered by $S$. aureus or $S$. epidermidis. Recovery of wound requires three stages which are inflammatory, proliferative and remodelling stages. Inflammatory stage is characterized with redness-swellingheat-pain, indicating immune response to prevent further infection. Proliverative stage is attempted to repair damaged tissue, visually recognized as scar development. Formation of new epithel layer also occurs at this stage. The last remodelling stage requires longer time to resume skin function and appearance (Demidova-Rice et al., 2012). Infection of $S$. aureus in wound is reported to inhibit formation of new epithelial layer. Schierle et al. (2009) reported that $S$. aureus develops slimy matrix in between wound gap, thus delaying progress of proliverative stage.

Proliferative stage was promoted by enhancement of skin regeneration. Study on ex vivo skin model indicates potency of cocoa polyphenol on generating skin extracellular matrix i.e. glycosaminoglycans and collagen type I, III and IV (Gasser et al., 2008). It was reported by Kapoor et al. (2004) that catechin gallate induces upregulation of vascular endothelial growth factor (VEGF), where VEGF is important in development in wound healing by stimulating accumulation and proliferation of 
endothelial cells (Bao et al., 2009). Interestingly, catechin maintains homeostasis of collagen production and prevents keloid formation due to overly accumulated collagen (Zhang et al., 2006).

Phenolic compound is also promoting stability extracellular matrix, namely collagen, towards environmental and enzymatic degradation. The number of galloyl group in phenolic compound contributes improvement of thermal stability of collagen (Madhan et al., 2007; Tang et al., 2003). Towards enzymatic degradation, polyphenol protects proteolysis of collagen by Matrix-Metalloproteinase (MMP). MMP is enzyme that degrades extracellular matrix such as collagen and gelatin. In inflammatory stage, MMPs is responsible for cleaning wound debridement and decaying proteins of pathogen. However, in proliferative stage, MMP inhibits establishment of collagens and delaying wound recovery even inducing wound chronicity (Muller et al., 2008; Mwaura et al., 2006). Procyanidins improves collagen structure by providing itself as connecting molecules between collagen helixes (He et al., 2011). The crosslinked formation protects collagen from MMP proteolysis (Zhai et al., 2011).

This study also implied potency of cocoa as source of active ingredients to be incorporated in skin care products. Activity of CEE to inhibit growth of S. aureus and S. epidermidis suggests its function to control population of skin normal flora. Furthermore, antiinflammatory and proliferative effect of CEE may contribute in skin regeneration and wound healing cosmetics.

\section{CONCLUSION}

Cocoa ethanolic extract demonstrated antibacterial activity against $S$. aureus and S. epidermidis through inhibition of bacteria growth. Eventhough the inhibitory activity was much lower than conventional first line antibiotics. Topical application of the cream containing cocoa ethanolic extract was effective in promoting contraction of cutaneous wound infected by both type of bacteria.

\section{ACKNOWLEDGEMENT}

The authors express gratitude to Indonesian Coffee and Cocoa Research Institute for funding and research facilities, and to Faculty of Medicine, University of Jember, for experimental design, ethical clearence and technical assistance.

\section{REFFERENCES}

Al-Habib, A.; E. Al-Saleh; A.-M. Safer \& M. Afzal (2010). Bactericidal effect of grape seed extract on methicillin-resistant Staphylococcus aureus (MRSA). The Journal of Toxicological Sciences, 35, 357-364.

Ali, N.H.; S. Faizi \& S.U. Kazmi (2011). Antibacterial activity in spices and local medicinal plants against clinical isolates of Karachi, Pakistan. Pharmaceutical Biology, 49, 833-839.

Bandele, O.J.; S.J. Clawson \& N. Osheroff (2008). Dietary polyphenols as topoisomerase II poisons: B ring and $\mathrm{C}$ ring substituents determine the mechanism of enzyme-mediated DNA cleavage enhancement. Chemical Research in Toxicology, 21, 1253-1260.

Bao, P.; A. Kodra; M. Tomic-Canic; M.S. Golinko; H.P. Ehrlich \& H. Brem (2009). The role of vascular endothelial growth factor in wound healing. Journal of Surgical Research, 153, 347-358.

Bell, S.M.; J.N. Pham \& T.T. Nguyen (2011). Antibiotic Susceptibility Testing by the CDS Method: A Manual for Medical and Veterinary Laboratories 2011. New South Woles, Australia.

Bernal, P.; S. Lemaire; M.G. Pinho; S. Mobashery; J. Hinds \& P.W. Taylor (2010). Insertion of epicatechin gallate into the cytoplasmic membrane of methicillin-resistant 
Staphylococcus aureus disrupts penicillin-binding protein (PBP) 2Amediated $\beta$-lactam resistance by delocalizing PBP2. Journal of Biological Chemistry, 285, 24055-24065.

Coutinho, H.D.; J.G. Costa; E.O. Lima; V.S. FalcãoSilva \& J.P. Siqueira (2009). Herbal therapy associated with antibiotic therapy: potentiation of the antibiotic activity against methicillin-resistant Staphylococcus aureus by Turnera ulmifolia L. BMC Complementary and Alternative Medicine, 9, 13.

Crozier, S.J.; A.G. Preston; J.W. Hurst; M.J. Payne, J. Mann; L. Hainly \& D.L. Miller (2011). Cacao seeds are a "Super Fruit": A comparative analysis of various fruit powders and products. Chemistry Central Journal, 5, 1-6.

Demidova-Rice, T.N.; M.R. Hamblin \& I.M. Herman (2012). Acute and impaired wound healing: pathophysiology and current methods for drug delivery, part 1: normal and chronic wounds: biology, causes, and approaches to care. Advances in Skin and Wound Care, 25, 304-314.

Dillinger, T.L.; P. Barriga; S. Escárcega; M. Jimenez; D.S. Lowe \& L.E. Grivetti (2000). Food of the gods: cure for humanity? a cultural history of the medicinal and ritual use of chocolate. Journal of Nutrition, 130, 2057-2072.

Dryden, M.S. (2009). Skin and soft tissue infection: microbiology and epidemiology. International Journal of Antimicrobial Agents, 34, 2-7.

García-Lafuente, A.; E. Guillamón; A. Villares; M.A. Rostagno \& J.A. Martínez (2009). Flavonoids as anti-inflammatory agents: implications in cancer and cardiovascular disease. Inflammation Research, 58, 537-552.

Gasser, P.; E. Lati; L.P. Mazzarino; D. Bouzoud; L. Allegaert \& H. Bernaert (2008). Cocoa polyphenols and their influence on parameters involved in ex vivo skin restructuring. International Journal of Cosmetic Science, 30, 339-345.
Hall-Stoodley, L.; J.W. Costerton \& P. Stoodley (2004). Bacterial biofilms: from the natural environment to infectious diseases. Nature Reviews Microbiology, 2, 95-108.

Hay, R.J.; N.E. Johns; H.C. Williams; I.W. Bolliger; B. Delavalle; D.J. Margolis \& M.. Naghavi (2013). The global burden of skin disease in 2010: An analysis of the prevalence and impact of skin conditions. Journal of Investigative Dermatology, 134, 1527-1534.

He, L.; C. Mu; J. Shi; Q. Zhang; B. Shi \& W. Lin (2011). Modification of collagen with a natural cross-linker, procyanidin. International Journal of Biological Macromolecules, 48, 354-359.

Johnson, B.J.; J.B. Delehanty; B. Lin \& F.S. Ligler (2008). Immobilized proanthocyanidins for the capture of bacterial lipopolysaccharides. Analytical Chemistry, 80, 2113-2117.

Kapoor, M.; R. Howard; I. Hall \& I. Appleton (2004). Effects of epicatechin gallate on wound healing and scar formation in a full thickness incisional wound healing model in rats. The American Journal of Pathology, 165, 299-307.

Lee, K.W.; Y.J. Kim; H.J. Lee \& C.Y. Lee (2003). Cocoa has more phenolic phytochemicals and a higher antioxidant capacity than teas and red wine. Journal of Agricultural and Food Chemistry, 51, 7292-7295.

Li, K.; Y. Diao; H. Zhang; S. Wang; Z. Zhang; B. Yun; S. Huang \& H. Yang (2011). Tannin extracts from immature fruits of Terminalia chebula Fructus Retzz promotes cutaneous wound healing in rats. BMC Complementary and Alternative Medicine, 11, 86.

Lippi, D. (2009). Chocolate and medicine: Dangerous liaisons? Nutrition, 25, $1100-1103$.

Luciano-Montalvo, C.; I. Boulogne \& J. GavillánSuárez (2013). A screening for antimicrobial activities of Caribbean herbal remedies. BMC Complementary and Alternative Medicine, 13, 126. 
Madhan, B.; G. Krishnamoorthy; J.R. Rao \& B.U. Nair (2007). Role of green tea polyphenols in the inhibition of collagenolytic activity by collagenase. International Journal of Biological Macromolecules, 41, 16-22.

Matsumoto, Y.; Kaihatsu; K. Nishino; M. Ogawa; N. Kato \& A. Yamaguchi (2012). Antibacterial and antifungal activities of new acylated derivatives of epigallocatechin gallate. Frontiers in Microbiology, 3, 1-10.

Miller, K.B.; W.J. Hurst; M.J. Payne; D.A. Stuart; J. Apgar; D.S. Sweigart \& B. Ou (2008). Impact of alkalization on the antioxidant and flavanol content of commercial cocoa powders. Journal of Agricultural and Food Chemistry, 56, 8527-8533.

Misnawi; J. Selamat; J. Bakar \& N. Saari (2002). Oxidation of polyphenols in unfermented and partly fermented cocoa beans by cocoa polyphenol oxidase and tyrosinase. Journal of the Science of Food and Agriculture, 82, 559-566.

Misnawi; T. Wahyudi; A.B.T. Sari; D.C. Mufida; A.R. Setiawan \& A. Isnaini (2015). The antidysentery properties of Theobroma cacao L. Food Studies, 4, 16-23.

Muler, M.; C. Trocme; B. Hardy; F. Morel; S. Halimi \& P. Benhamon (2008). Matrix metallo protein and diabetic foot ulcers: the ratio of MMP-1 to TIMP-1 is a predicator or wond healing. Dibetic Medicine, 15, 419-426.

Mwaura, B.; B. Mahendran; N. Hynes; D. Defreitas; G. Avalos; T. Adegbola; M. Adham; C. Connolly \& S. Sultan (2006). The impact of differential impression of extracellular matrix metalloproteinase inducer, matrix metalloproteinase-2 tissue inhibitor of matrix metalloproteinase- 2 and PDGF-AA on the chronicity of venous leg ulcers. European Journal of Vascular and Endovascular Surgery, 31, 306-310.

Naveed, R.; I. Hussain; A. Tawab; M. Tariq; M. Rahman; S. Hameed; M.S. Mahmood; A.B. Siddique \& M. Iqbal (2013). Anti- microbial activity of the bioactive components of essential oils from Pakistani spices against Salmonella and other multi-drug resistant bacteria. BMC Complementary and Alternative Medicine, 13, 265.

Neukam, K.; W. Stahl; H. Tronnier; H. Sies \& U. Heinrich (2007). Consumption of flavanol-rich cocoa acutely increases microcirculation in human skin. European Journal of Nutrition, 46, 53-56.

Oh, J.; S. Conlan; E.C. Polley; J.A. Segre \& H.H. Kong (2012). Shifts in human skin and nares microbiota of healthy children and adults. Genome Medicine, 4, 77.

Otto, M. (2009). Staphylococcus epidermidisthe 'accidental' pathogen. Nature Reviews Microbiology, 7, 555-567.

Otto, M. (2012). Molecular basis of Staphylococcus epidermidis infections. Seminars in Immuno Pathology, 34, 201-214.

Puupponen-Pimiä, R.; L. Nohynek; H.-L. Alakomi \& K.-M. Oksman-Caldentey (2005). Bioactive berry compounds: novel tools against human pathogens. Applied Microbiology and Biotechnology, 67, 8-18.

Radulovic, N.; P. Blagojevic; Z. Stojanovic-Radic \& N. Stojanovic (2013). Antimicrobial plant metabolites: structural diversity and mechanism of action. Current Medicinal Chemistry, 20, 932-952.

Sari, A.B.T.; D.C. Mufida; N.N. Fatima; T.I. Hendrayati; T. Wahyudi \& Misnawi. (2014). In vitro antibacterial activity of cocoa ethanolic extract against Escherichia coli. International Food Research Journal, 21, 935-940.

Schierle, C.F.; M. De la Garza; T.A. Mustoe \& R.D. Galiano (2009). Staphylococcal biofilms impair wound healing by delaying reepithelialization in a murine cutaneous wound model. Wound Repair and Regeneration, 17, 354-359.

Singh, R.; P. Ray; A. Das \& M. Sharma (2010). Penetration of antibiotics through Staphylococcus aureus and Staphy- 
lococcus epidermidis biofilms. Journal of Antimicrobial Chemotherapy, 65, 1955-1958.

Suriyanarayanan, B.; K. Shanmugam \& R.S. Santhosh (2013). Synthetic quercetin inhibits mycobacterial growth possibly by interacting with DNA gyrase. Romanian Biotechnological Letters, 18, 8587-8593.

Tang, H.; A.D. Covington \& R. Hancock (2003). Structure-activity relationships in the hydrophobic interactions of polyphenols with cellulose and collagen. Biopolymers, 70, 403-413.
Zhai, W.-y.; C.-p. Jia; H. Zhao \& Y.-s. Xu (2011). Procyanidins inhibit tumor angiogenesis by crosslinking extracellular matrix. Chinese Journal of Cancer Research, 23, 99-106.

Zhang, Q.; A.P. Kelly; L. Wang; S.W. French; X. Tang; H.S. Duong \& A.D. Le (2006). Green tea extract and (-)-epigallocatechin3-gallate inhibit mast cell-stimulated type I collagen expression in keloid fibroblasts via blocking PI-3K/Akt signaling pathways. Journal of Investigative Dermatology, 126, 2607-2613.

$* * 0 * *$ 